\title{
Two-compartment models of spasticity in spinal motor neurons following spinal cord injury Mini Kurian ${ }^{* 1}$ and Sharon Crook ${ }^{1,2}$
}

Address: ${ }^{1}$ Center for Adaptive Neural Systems, Biodesign Institute \& Department of Mathematics and Statistics, Arizona State University, Tempe, AZ 85287, USA and ${ }^{2}$ School of Life Sciences, Arizona State University, Tempe, AZ 85287, USA

Email: Mini Kurian* - kurian@mathpost.la.asu.edu

* Corresponding author

from Sixteenth Annual Computational Neuroscience Meeting: CNS*2007

Toronto, Canada. 7-12 July 2007

Published: 6 July 2007

BMC Neuroscience 2007, 8(Suppl 2):PI0I doi:I0.1/86/I47I-2202-8-S2-PI0I

(C) 2007 Kurian and Crook; licensee BioMed Central Ltd.

Spasticity is characterized by hyperreflexia, clonus and hypertonic musculature and is an impediment to functional locomotor recovery after spinal cord injury (SCI). It is known that the structure and biophysical properties of motoneurons are altered following SCI; however, the physiological mechanisms underlying spasticity are not well understood. Under control conditions motoneurons can produce plateau potentials, which are sustained depolarizations triggered by brief synaptic inputs. These plateau potentials are mediated by L-type calcium currents and are known to cause bistable behavior in the motoneurons of brain-stem intact animals and humans. This bistable behavior endows motoneurons with a mechanism for translating short lasting synaptic inputs into long lasting motor output [1]. During the acute stage following SCI, rat motoneurons lose the endogenous ability to generate plateau potentials but at chronic stages the plateau potentials reappear [2]. Voltage gated persistent sodium and calcium currents (PICs) have been identified as the cause of plateau potentials in the chronic stage following
SCI [3]. In the presence of PICs, a brief stimulus can produce self sustained firing.

Two-compartment models with Hodgkin-Huxley type channel kinetics were constructed to mimic motoneuron dynamics for the control case and for the acute and chronic stages following SCI. Table 1 shows the channels used in constructing the motoneuron models.

Experimental data for injected ramp currents and injected pulse currents were used to constrain the model parameters [2]. Computational studies were used to systematically investigate the mechanisms underlying the generation of plateau potentials and the firing properties in the three cases including: the influences of the specific ionic currents, the coupling strength between the somatic and dendritic compartments, and the relative sizes of the two compartments.

Table I: Motoneuron model currents.

\begin{tabular}{lll}
\hline Motoneuron & Soma Channels & Dendritic Channels \\
\hline Control & $I_{\text {Na }}, I_{K-d r}, I_{C a-N}, I_{K(C a)}, I_{\text {Leak }}$ & $I_{C a-N}, I_{C a-L}, I_{K(C a)}, I_{\text {Leak }}$ \\
Acute & $I_{\mathrm{Na}}, I_{K-d r}, I_{C a-N}, I_{K(C a)}, I_{\text {Leak }}$ & $I_{C a-N}, I_{K(C a)}, I_{\text {Leak }}$ \\
Chronic & $I_{\text {Na }}, I_{K-d r}, I_{C a-N}, I_{K(C a)}, I_{\text {Leak }}$ & $I_{C a-N}, I_{C a-P} I_{\text {Na-P }}, I_{K(C a)}, I_{\text {Leak }}$ \\
\hline
\end{tabular}




\section{References}

I. Heckman CJ, Gorassini MA, Bennett DJ: Persistent inward currents in motoneurons dendrites: implications for motor output. Muscle Nerve 2004, 3 I: I35-I56.

2. Bennett DJ, Li Y, Siu M: Plateau potentials in sacrocaudal motoneurons of chronic spinal rats recorded in vitro. $J \mathrm{Neu}$ rophysiol 200I, 86: 1955-197I.

3. Li Y, Bennett DJ: Persistent sodium and calcium currents cause plateau potentials in motoneurons of chronic spinal rats. J Neurophysiol 2003, 90:857-869.

Publish with Biomed Central and every scientist can read your work free of charge

"BioMed Central will be the most significant development for disseminating the results of biomedical research in our lifetime. " Sir Paul Nurse, Cancer Research UK

Your research papers will be:

- available free of charge to the entire biomedical community

- peer reviewed and published immediately upon acceptance

- cited in PubMed and archived on PubMed Central

- yours - you keep the copyright 